\title{
Penetrating cervical spine injury and spinal cord intramedullary abscess
}

\author{
Trauma raquimedular penetrante e abscesso medular
}

\section{Regis Tavares da Silva1, Henrique Caetano de Souza', Ricardo de Amoreira Gepp', Giovani Rodrigues \\ Batista², Thomas Anthony Horan³, Paulo Cesar Rocha Oliveira ${ }^{2}$}

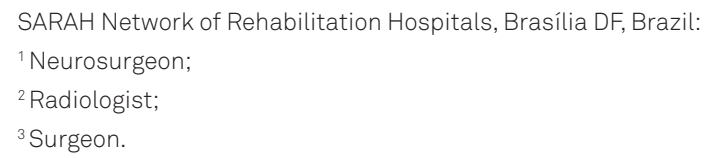

Correspondence: Paulo Cesar Rocha Oliveira; Diagnostic Imaging Department, Hospital SARAH - Brasília; SARAH Network of Rehabilitation Hospitals; SMHS Qd 501 / Bl A; 70335-901 Brasilia DF - Brasil; E-mail: bsbpaulocesar@gmail.com

Conflict of interest: There is no conflict of interest to declare.

Received 07 October 2011; Received in final form 28 November 2011; Accepted 05 December 2011

Penetrating spinal injuries by wooden foreign body (WFB) is rare ${ }^{1}$. We present a 52 year-old man with a cervical spine injury by a WFB, identified 172 days after the accident, with an intramedullary abscess. Surgical intervention and antibiotic treatment led to neurological improvement.

\section{CASE}

A 52 year-old man had fallen from a horse on May 29, in 2008 , with a penetrating injury from a piece of wood below the angle of the left mandible causing prompt change in sensibility and strength in his left side. He underwent a superficial exploration and suture in the local hospital. Neurological deficits evolved over time to loss of independent gait and severe functional limitations of the upper limbs, particularly the left.

He was admitted on October 13, in 2008, without signs of inflammation, dehiscence, or cerebrospinal fluid (CSF) fistula in the neck. Neurological examination showed tetraparesis, predominantly on the left side, and hyperreflexia in lower limbs with preserved vibration and position sensation in all four limbs. He was only able to walk with great difficulty if supported by two helpers. Bladder and bowel functions were normal.

The magnetic resonance image (MRI) revealed spinal cord edema and a heterogeneous intramedullary lesion at C4-C5 level, with ring like post-contrast enhancement, consistent with an abscess (Fig A and B). There was a hypointense linear image within the left C4-C5 intervertebral foramen with intramedullary extension and hyperdense on computed tomography, measuring $3.0 \mathrm{~cm}$, consistent with a WFB. It transfixed the ipsilateral vertebral artery, which was obliterated (Fig C and D).
The WFB was surgically removed (Fig E). Purulent matter was drained from location, where the WFB had been lodged. Lab work showed the presence of Staphilococcus epidermiditis, and the patient was treated with oxacillin. At the latest outpatient follow-up visit on January $18^{\text {th }}$, 2011, he was independent for activities of daily living, walking without any aid, with intact sphincter control.

\section{DISCUSSION}

Non-missile penetrating spinal injuries are more commonly caused by stabs ${ }^{2}$. WFB is rarely reported as the cause of this type of injury ${ }^{1}$. Since the wood is an optimal source of infection due its porous, soft, organic, and vegetable nature, spinal infectious complications are prone to occur ${ }^{1,3}$. Foreign body reaction, another inflammatory complication, may lead to long-term neurological worsening ${ }^{1}$.

CT and MRI are essential to evaluate spinal cord and the presence of a foreign body in penetrating spinal injuries. The density of wood on $\mathrm{CT}$ is highly variable and depends on its type and hydration status, as well as on the length of stay in the body ${ }^{4}$. This latter factor may explain the increased density of the wooden fragment in this patient. MRI is mandatory in non-missile penetrating spinal injuries for the diagnosis of associated lesions ${ }^{5}$, whenever a metallic foreign body has been excluded or removed ${ }^{2}$. Even when CT is negative, MRI should be performed to exclude retained foreign bodies ${ }^{1}$.

Treatment of penetrating spinal injuries by WFB requires antibiotic administration to prevent or treat infectious complications, and surgery, to decompress the spinal cord, to remove the foreign body, and to prevent CSF leakage $e^{1,3,5}$. 



Fig. Preoperative magnetic resonance image and computed tomography. (A) MR Sagittal T2. (B) fat-saturated contrast-enhanced sagittal T1 images showing an intramedullary abscess and adjacent swelling. (C) MR axial T2 image at C4-C5 level reveals linear hypointense structure within the left intervertebral foramen, with low signal intensity and intramedullary tip. Note the absence of flow void in the left vertebral artery (asterisk). (D) computed tomography oblique axial slice with soft tissue window settings demonstrates a high-density linear image crossing the left intervertebral foramen at C4-C5 level. (E) photograph of the wooden foreign body.

\section{References}

1. Gul S, Dusak A, Songur M, Kalayci M, Acikgoz B. Penetrating spinal injury with a wooden fragment: a case report and review of the literature. Spine 2010;35:1534-1536.

2. Jacobsohn M, Semple P, Dunn R, Candy S. Stab injuries to the spinal cord: a retrospective study on clinical findings and magnetic resonance imaging changes. Neurosurgery 2007;61: 1262-1266.

3. Piqueras C, Martínez-Lage JF, Almagro MJ, Ros De San Pedro J, Torres
Tortosa P, Herrera A. Cauda equina-penetrating injury in a child. Case report.J Neurosurg 2006;104:279-281.

4. Ginsberg LE, Williams DW, Mathews VP.CT in penetrating craniocervical injury by wooden foreign bodies: reminder of a pitfall. AJNR Am J Neuroradiol 1993;14:892-895.

5. Pal D, Timothy J, Marks P. Penetrating spinal injury with wooden fragments causing cauda equina syndrome: case report and literature review. Eur Spine J 2006;15:574-577. 